\title{
Vocational interest profile by candidates of Job and Occupation Consultants
}

\author{
Kaan Zülfikar DENİ*
}

\begin{abstract}
This study was conducted in accordance with certain objectives and some of them are to determine the interest of these individuals especially in the psychological aspect of this profession, to examine the difference between their interests on the basis of gender, to learn their opinions about their department and why they want to become a JOC. The participants of this study were the JOC candidates who attended 360 hours Job and Occupation Consultancy training at Ankara University. The participant group composed of 216 individuals, while 140 of them were female, 73 of them were male. Also 3 participants did not specified their gender. The data of this study were collected by means of Occupational Field Interest Inventory (OFII) that was administered in classroom setting and certain questions were attached to this inventory. The data were analyzed using Pearson correlation formula, independent samples $t$ test and descriptive statistics. As a result of the study, significant differences were found to be high in the advantage of male participants in Computer, Engineering, Political - Financial Sciences areas and in the advantage of female participants in Psychology, Visual Arts and Health areas, similarly in the literature. While only $14 \%$ of the participants stated that they wanted to study psychology by taking into account their interests, it was rated above the average from interest sub-set of $60 \%$ of them.
\end{abstract}

Keywords: Job and Occupation Consultancy, Occupational Field Interest Inventory, interest of psychology, choice of occupation.

\footnotetext{
* Assist. Prof. Dr., Ankara University, Institute of Educational Sciences, Ankara, Turkey. E-mail: zlfkrdnz@yahoo.com
} 


\section{SUMMARY}

Purpose and Significance: Although Job and Occupation Consultancy is a very widespread profession abroad, it has been a quite new profession in Turkey. In Turkey, individuals tend to prefer departments that promise a job instead of studying a branch that appeals to their interest due to unemployment concerns. It is aimed that Job and Occupation Consultants (JOC) guide individuals towards professions as per their interests and personal characteristics. It requires knowledge about JOCs and their profiles since this profession has been structured very lately. This study was conducted in accordance with certain objectives and some of them are to determine the interest of these individuals especially in the psychological aspect of this profession, to examine the difference between their interests on the basis of gender, to learn their opinions about their department and why they want to become a JOC.

Method: 216 JOC candidates that had attended 360 hours Job and Profession Consultancy training at Ankara University participated in the study. The participant group composed of 216 individuals, while 140 of them were female, 73 of them were male. Also 3 participants did not specified their gender. $86 \%$ of the participants were graduates of a mathematics or science department. However, they received JOC training in a different area that requires direct work with people due to the employment concerns. Moreover, 25 individuals out of this group stated their negative or positive ideas about their own department and this knowledge was gathered by using open ended questions. The data of this study were collected by means of Occupational Field Interest Inventory (OFII) that was administered in classroom setting and certain questions were attached to this inventory. The data were analyzed using Pearson correlation formula, independent samples t test and descriptive statistics.

Results: In the study, while the interests of individuals in all sub-sets of OFII were determined, their interests in the sub-dimension of Psychology related to the job that they would perform were also determined. It was observed that Psychology interest rate of $60 \%$ of the participants were above the average. The majority of participants wanted to become a JOC due to unemployment concerns although they were the graduates of mathematics and science departments. As a result of the study, the significant differences were found to be high in the advantage of male participants in Computer, Engineering, Political - Financial Sciences areas and in the advantage of female participants in Psychology, Visual Arts and Health areas. A moderately significant correlation was found between degrees of loving the area of graduation and interest point pertaining to that area. Majority of participants stated that they didn't study in a department as per their interests. Only 14\% of participants stated that they wanted to study Psychology. 
Discussion and Conclusions: When the findings are examined, the significant differences that are high in the advantage of male participants in areas of Computer, Engineering, Political - Financial Sciences and in the advantage of female participants in areas of Psychology, Visual Arts and Health that are some of the subsets of OFII with occupational roles determined by society according to gender appear to be appropriate. When the literature is reviewed, it can be seen that women prefer occupations that involve communication with people while men prefer occupations that involve working with objects or abstract concepts. While only $14 \%$ of the participants stated that they wanted to study psychology taking into account their interests, it was rated above the average from interest sub-set of $60 \%$ of them. Moreover, it was observed that the majority of participants did not study in a department that appealed to their interests. It can be suggested that knowledge of JOCs should be reinforced in this respect since they will have to guide individuals according to their interests in the near future. Since this study was conducted on mathematics and science group, it can be repeated on different groups. 


\section{İş ve Meslek Danışmanı Adaylarının Mesleki İlgi Profili}

\section{Kaan Zülfikar DENIZ*}

ÖZ. İş ve Meslek Danışmanı (IMD), bireylerin kendilerini tanımalarına (kişilik özellikleri, yetenek, ilgi, beklenti vb. açısından), iş ve meslekler hakkında bilgi sahibi olmalarına, kişilikleriyle mesleğin gerektirdiği bilgileri karşılaştırmalarına ve böylece doğru mesleğe yönelmelerine yardımcı olacak kişilerdir. Dolayısıyla bu konularda yardım ihtiyacı olan bireylere danışmanlık yapacaklardır. Danışmanlık hizmeti veren kişilerin mesleğini isteyerek ve ilgisine uygun olarak seçmesi çok önemlidir. Bu çalışmada İMD adaylarının kendi mezun oldukları bölüm, bölümlerini sevme dereceleri ve cinsiyete göre ilgi puanları arasındaki ilişki ve farklılıklar incelenmiştir. Ayrıca kendi bölümlerini ne derece ilgilerine uygun seçtikleri ve bölümlerine ilişskin görüşleri açık uçlu sorularla alınmıştır. Araştırmada Mesleki Alan İlgi Envanteri (MAİ) kullanılmışıtır. Araştırmaya Ankara Üniversitesi'nde İMD eğitimi alan 216 kişi katılmıştır. Çalışma sonucunda Bilgisayar, Mühendislik, Siyasal-Mali Bilimler alanlarında erkekler lehinde yüksek, Psikoloji, Görsel Sanatlar ve Sağlık alanlarında ise kadınlar lehinde yüksek olmak üzere anlamlı farklılıklar gözlenmiştir. Mezun oldukları alanı sevme dereceleri ile o alana ait ilgi puanları arasında orta düzeyde anlamlı korelasyon bulunmuştur. Katılımcıların büyük çoğunluğu ilgisine uygun bir bölümde okumadığını belirtmiştir. Ayrıca katılımcıların MAİ'nin Psikoloji alt boyutuna ilişkin puanları incelenmiş ve çoğunluğunun ilgi puanlarının ortalamanın üzerinde toplandığı görülmüştür.

Anahtar Sözcükler: İş ve Meslek Danışmanı, Mesleki Alan İlgi Envanteri (MAİ), psikoloji ilgisi, meslek seçimi.

\footnotetext{
* Yrd. Doç. Dr., Ankara Üniversitesi Eğitim Bilimleri Enstitüsü Ankara, Türkiye.

E-posta: zlfkrdnz@yahoo.com
} 


\section{GíRiş}

London, Würzburg ve Berne (1972) mesleki tercihi, belirli bir grup ya da çeşitli mesleklerden birini seçme süreci olarak tanımlanmakta ve mesleki tercihte etkili olan öznel ve nesnel etkenleri belirtmektedir. Öznel etkenler ilgi, istek, yetenek ve sosyal statü; nesnel etkenler ise, ücret, gelir ve yükselme gibi sosyal güvence ve ekonomik getiri olarak belirtilmektedir. Çalışanlar seçim yaparken, işyerinin yeri, ortalama ücreti, sosyal avantajları, meslektaşlarının özellikleri ve işin ne kadar kolay yapıldığ 1 gibi etkenlere dikkat ederler. Meslek seçimi insanların yaşamında önemli bir yer tutmaktadır. Bireyler mesleklerini seçerken aynı zamanda yaşam tarzlarını da seçmektedirler.

Meslek seçimi genellikle ergenlik döneminin görevlerinden birisidir. Vondracek ve Skorikov (1997) ilgilerin, ergenlikte mesleki ve genel kimlik gelişiminde önemli rol oynayıp kariyer seçimlerinde de bireylere rehberlik ettiğini belirtmektedir. $\mathrm{Bu}$ araştırmacılara göre ergenlik dönemi bireyin kendini mesleki kimlik açısından tanıdığı, ardından geleceğine ve gelecekte alacağı rollere yöneldiği ve bu rolleri denediği bir dönemdir. Bu dönemdeki bireylere işle ilgili gerçekçi etkinliklerin sunulması gerektiği ve özellikle de ergenliğin orta dönemlerindeki bireylerin meslek seçimi konusunda okuldaki etkinliklerden çok etkilendiği vurgulanmaktadır. Repetto, Malik, FerrerSama, Manzano ve Hiebert (2003) ise bireyin hedeflerinin belirlenmesinde; değerlerin, ilgilerin ve kariyer kararlarının sürekli gözden geçirilmesi gerektiğini vurgulamaktadır. $\mathrm{Bu}$ yapılan işlem kariyer danışmanlığının çalışma alanında yer almaktadır. OECD raporunda (2004) kariyer danışmanlığından en az yararlanan grupların ilköğretim ve meslek liseleri olduğu vurgulanmaktadır. Raporda yönetici ve siyasetçilere kariyer danışmanlığının geliştirilmesi için önerilere de yer verilmektedir.

Lokan (1997) ilgilerin meslek seçiminde kilit bir rol oynadığını ve davranış örüntüleri, davranışlarımızın sonuçları, etkinlikler, öncelikler, kendini algılama ve kişilik açıları gibi farklı şekillerde tanımlandığını belirtmektedir. Mesleki ilgi kavramı üzerine farklı tanımlar yapılmakla birlikte bu tanımlar arasında çok ciddi farklılıklar gözlenmemektedir. Tanımların ortak noktası bireyin meslekler ya da mesleklerle alakalı etkinliklere karşı gösterdiği hoşlanırım, hoşlanmam veya fark etmez şeklindeki tepkileridir (Holland, 1985; Savickas, 1999; Herr ve Cramer, 1996). Betsworth ve Fouad (1997) mesleki ilgilerin kariyer gelişiminin merkezinde yer aldığını belirtip Hansen (1984)'den ilginin beş temel noktasını (1)ïlgilerin çevre ve sosyal etkilerle ortaya çıktığı, (2)ílgilerin genetik olduğu, (3)İlgilerin bir kişilik özelliği olduğu, (4)İlgilerin güdü, dürtü ya da ihtiyaç olduğu, (5)İlgilerin benliğin yansıması olduğunu 
aktarmaktadır. Low ve Rounds (2007) mesleki ilgilerin ergenlik boyunca aile, okul ve akranların yönlendirmesi kadar kimlik oluşumu, bilişsel, sosyal ve duygusal gelişim, hormonal, psikolojik ve bedensel değişim gibi özelliklerden de etkilendiğini belirtmektedir. Türkiye'ye özgü olarak ise, bireyler meslek seçiminde ilgilerinden çok üniversiteye giriş sınavındaki puanı tutan programlar arasından yani sınavdaki başarısını dikkate alarak tercih yapmaktadir.

Frank Parson tarafından 1909'da bireyle iş çevresi arasında uyumun savunulmasının ardından Strong tarafından geliştirilen ilk ilgi envanteri ile mesleki ilginin tarihçesi başlamıştır. Günümüzde Holland tarafından ortaya atılan mesleki özellikler ve çalışma ortamı kuramı en iyi birey-çevre etkileşimini yansıtan kuramdır (Low ve Rounds, 2006). Holland'ın kuramı o kadar yaygınlaşıp kabul gördüğü içini - ilk ilgi envanterini geliştiren Strong'un ölçekleri de dahil olmak üzere - Holland'dan önce ve sonraki pek çok ilgi envanterinin boyutları Holland'ın kuramına göre düzenlenmiştir.

Türkiye'de mesleki ilgilerin ölçülmesiyle ilgili çalışmalar dünya literatüründeki bu yoğunluğun aksine oldukça sı ğ görünmektedir. Bunun sebebi meslek seçme aşamasında olan üniversite adaylarının yalnızca bilgi ve yeteneklerini dikkate alan bir sinavla üniversiteye geçiş yapmaları olabilir. Bilgi ve yetenek ölçümüne odaklanan üniversite adayları, aileleri ve akademisyenler ilgileri ihmal etmiş olabilirler. Bu sınırlı çalışmalar içinde Bütün (1998) çalışmasında kız öğrencilerin ilgilerini belirlemede anne-baba mesleği, eğitimi, doğum sırası gibi değişkenlerle birlikte SED'in de etkili olduğu sonucuna ulaşmıştır. Sayın (2000) ise Bütün'den farklı değişkenleri kullanarak yaptığı, mesleki ilgileri yordayan değişkenleri ortaya koyan çalışmasında, cinsiyetin, mesleki olgunluğun, yaşın, sosyal desteğin, denetim odağının, sınava girilecek puan türünün ve dershanelerin niteliğinin mesleki ilgileri yordadığ 1 sonucuna ulaşmıştır. Öktem (2000) de yaptığ 1 çalışmada lise son sınıf öğrencilerinin algıladıkları ana-baba tutumlarının mesleki ilgi ve değerlerini etkilediğini ve ana-baba tutumları değiştikçe farklı ilgi ve değerlerin ön plana çıktığı sonucuna ulaşmıştır. Uzer (1987) çalı̧̧masında k1z öğrencilerin erkek öğrencilere göre ilgilerine daha uygun tercihte bulundukları sonucuna ulaşmıştır. Yaman, Gerçek ve Soran (2008) biyoloji ögretmen adaylarının mesleki ilgileri ile akademik başarıları arasında anlamlı bir ilişki olduğu ve son sınıf öğrencilerinin mesleki ilgilerinin daha yüksek olduğu bulgusuna ulaşmışlardır. Bunlara ek olarak Deniz (2008, 2009) tarafından bu araştırmada da kullanılan Mesleki Alan İlgi Envanteri geliştirme çalışması yapılmıştır. Deniz (2013) Mesleki Alan İlgi Envanteri'nin ulusal standardizasyon çalışmasını Türkiye'de eğitime devam eden 13-20 yaşları arasındaki bireyleri temsil eden 3799 kişi üzerinde yapmiştır. 
"İş ve Meslek Danışmanlığı hizmeti, İŞKUR tarafından, kişilerin özellikleri ile mesleklerin ve işyerlerinin gerektirdiği nitelik ve şartları karş1laştırarak, bireyin istek ve durumuna en uygun iş ve mesleği seçmesi, seçtiği meslek ile ilgili eğitim olanaklarından yararlanması, işe yerleştirilmesi, işe uyumunun sağlanması ile ilgili sorunların çözümüne sistemli olarak yardım edilmesi" şeklinde tanımlanmaktadır. İş ve meslek danışmanlığı hizmeti veren iş ve meslek danışmanı (IMD), bireylerin kendilerini tanımalarına (kişilik özellikleri, yetenek, ilgi, beklenti vb. açısından), iş ve meslek hakkında bilgi sahibi olmalarına, kişisel bilgileriyle mesleğin gerektirdiği bilgileri karşılaştırmalarına ve böylece en uygun iş veya mesleki eğitime yönelmelerine yardımcı olmalıdır. İMD'lerin hedef kitlesi ise mesleğini seçmeye çalışan, mesleğini değiştirmek veya geliştirmek isteyen, liselerde alan seçen ve bunun dışında bir meslek ve eğitim programı seçmede yardıma ihtiyaç duyan bireyler olarak belirtilmektedir (İŞKUR, 2012).

İş ve meslek danışmanlığg hizmetleri sayesinde kişilerin özellikleri ile mesleklerin gerektirdiği şartlar karşılaştırılarak bireyin istek ve durumuna en uygun iş ve mesleği seçmesi, bu meslekle ilgili eğitim imkanlarından yararlanması, işe uyumunun sağlanması ve işe yerleştirilmesiyle ilgili sorunların çözümüne sistemli olarak yardım edilebilmektedir (IMD Hizmetleri, 2012). Gelişmiş ülkelerde İMD'ler işsizlikle mücadeleye katılmaktadır. İŞKUR'daki İMD sayısı ise şu anda 393'tür. İŞKUR yeni IMMD'lerin istihdamını sağlamak için 16 ilde eğitim yapmıştır. 2010 KPSSP3 puanına göre 70 ve üzerinde puan alanlardan 3500 kişi eğitime alınmıştır. Bunlardan 2000'i ilk etapta İŞKUR'a İMD olarak atanmıştır (İŞKUR'dan İş ve Meslek Danışmanlığı Eğitimi, 2012). Son dönemde hız kazanan mesleki rehberlik ve kariyer danışmanlığının Türkiye'deki geçmişini Yeşilyaprak (2012) Başlangıç (1953-1975), Arayış (1976-1994) ve Gelişme (1995-2010) dönemi olarak aktarmaktadır.

İş ve meslek danışmanının danışanlara yardımcı olabilmesi için öncelikle kendini tanıması ve kendini tanımanın anlamını özümsemiş olması gerekir. Bireylere yardımcı olma istek ve ilgisinin de olması gerekmektedir. İMD adaylarının psikoloji bilimine yakınlığı ve ilgi duyma düzeyleri onların mesleğin özellikleriyle kendi özelliklerini eşleştirmelerinde ve işlerine uyum sürecinde etkili olacağı düşünülmektedir.

$\mathrm{Bu}$ çalışmanın amacı, İMD adaylarının şu anki mesleki ilgilerini belirlemek, mezun oldukları bölümlerle ilgilendikleri bölümler arasındaki farklılıkları ortaya koymak ve cinsiyete göre mesleki ilgilerinde anlamlı bir fark olup olmadığını tespit etmektir. Çalışmada bireylerin Mesleki Alan İlgi Envanteri (MAI)'nin Psikoloji alt boyutundan aldıkları puanlara ilişkin bulgulara da yer verilmiştir. Çünkü İMD adayları bireylere meslekler konusunda rehberlik edecektir. Mezun oldukları alanlara ilişkin ilgi profillerinin düzeyi de çalışma içinde ele alınmıştır. 


\section{YÖNTEM}

\section{Araştırma Modeli}

$\mathrm{Bu}$ araştırma var ola durumu açılamayı amaçlayan betimsel tarama modelinde bir çalışmadır.

\section{Katılımcilar}

Araştırmanın çalışma grubunu, 2011 yılında İŞKUR tarafından yürütülen İMD Kursu'na Ankara Üniversitesi'nde katılan 216 İMD aday1 oluşturmaktadır. Kursa 16 grupta toplam 400 öğrenci katılmıştır. Kat1limc1lar KPSS P3 puan türünde en yüksek puan alanlar arasından seçildiğinden ve KPSS P3 puan türünde yüksek puan almanın temel kriteri çok iyi bir matematik bilgisi olduğu için katılımcıların büyük çoğunluğu (185 kişi (\%86)) sayısal bölüm mezunudur.

Uygulama sırasında bütün gruplara ulaşılmış ancak katılımın zorunlu tutulmaması sebebiyle ölçeği tam ve doğru şekilde doldurmuş olan 216 ögrencinin bilgileri üzerinden analizler yapılmıştır. Bunlardan $140(\% 65)$ '1 kadın ve bunların yaş ortalaması 27,18; 73 (\%35)'ü erkek ve bunların yaş ortalaması 27,27'dir. Kadınların yaşları 23 ile 38; erkeklerin yaşları 22 ile 36 arasında olmakla birlikte kadınların \% 90'1 23 ile 31 yaş aralığında, erkeklerin \%90’ı 22 ile 31 yaş aralığında yığılma göstermişlerdir. Görüldüğü gibi yaş ortalamaları birbirine oldukça yakındır. Katılımcılardan 3 (\%1)'ü ise cinsiyetini belirtmemiştir.

\section{Veri Toplama Araçları}

Araştırmada Deniz $(2008,2009)$ tarafından geliştirilen Mesleki Alan İlgi Envanteri (MAİ) kullanılmıştır. Bireylerin mesleki ilgilerini tespit etmeyi amaçlayan bu ölçme aracı hakkında aşağıda bilgi verilmektedir.

\section{Mesleki Alan İlgi Envanteri (MAİ)}

Mesleki Alan İlgi Envanteri bireylerin 14 mesleki alana yönelik ilgilerini ölçmeyi amaçlamaktadır. Bu alanlar Matematik, Bilgisayar, Yabanc1 Dil, Görsel Sanatlar, Psikoloji, Eğitim, Türk Dili, Hukuk, Ziraat, İletişim, Mühendislik, Siyasal-Mali Bilimler, Fen Bilimleri, Sağlık Bilimleri olarak adlandırılmaktadır. 156 maddeden oluşan ölçeğin cevaplama şekli 5'li Likert tipi derecelemedir. Araştırmaya katılan birey maddeleri okuduktan sonra ilgisine göre çok ilgimi çeker (5)'den çok az ilgimi çeker (1)'e kadar olan derecelerden kendisine en uygun olanı işaretlemektedir. 
MAİ'nin geçerlik çalışmalarına yönelik olarak 14 farklı alanın her birinden alanında en az doktora derecesine sahip en az üç akademisyen olmak üzere toplamda 88 akademisyenden maddelerin alanlarını yansıtması hakkında görüş alınmıştır. Bunun yanı sıra ölçeğin yapı geçerliğine yönelik olarak önce açımlayıcı faktör analizi yapılmıştır. Bu analiz sonucunda 14 faktörün toplam varyansın \%49'unu açıkladığı sonucuna ulaşılmıştır. Daha sonra doğrulayıcı faktör analizi yapılmış ve uyum indekslerinin 0,87 ile 0,99 arasında değer aldığı görülmüştür. Yapı geçerliğinin bir başka kanıtı olarak ölçeğin 14 boyutunun kendi aralarındaki korelasyonları hesaplanmıştır. Hesaplanan korelasyonların medyanı $\mathrm{r}=0,07$ olmak üzere değerlerin $-0,43$ ile 0,50 arasında değer aldığ 1 görülmüştür. Bu sonuç da boyutların birbirinden yeterince ayrıştığının kanıtı olarak yorumlanmıştır.

MAİ'nin güvenirlik çalı̧̧malarına yönelik olarak önce iç tutarlılık güvenirliği (Cronbach alfa) tespit edilmiştir. Her boyut için hesaplanan Cronbach alfa değerinin 0,79 (Ziraat) ile 0,95 (Hukuk) arasında değiştiği, güvenirliklerin medyan değerinin ise 0,89 olduğu gözlenmiştir. Güvenirlik için bir başka kanıt MAİ 156 maddelik form oluşturulduktan sonra test tekrar test güvenirlik değeri hesaplanmıştır. Test tekrar test sonucunda elde edilen güvenirlik değerleri 0,75 (Ziraat) ile 0,95 (Hukuk) arasında değiştiği, medyan değerinin ise 0,89 olduğu görülmüştür (Deniz, 2009).

$\mathrm{Bu}$ bilgiler doğrultusunda 156 maddelik MAİ formunun mesleki alanı tespit etmede kullanılan geçerli ve güvenilir bir envanter olduğu sonucuna ulaşılmakla birlikte MAİ'nin tercih edilmesinin sebebi Türkiye'de geçerlik ve güvenirlik çalışması yapılmış en güncel mesleki ilgi envanterlerinden biri olmasidir.

Ayrıca uygulama öncesinde ölçeğe yaş, cinsiyet, mezun olduğu alan, mezun olduğu alanı sevme derecesi (0-100 arasında), yapmak istediği meslek gibi demografik bilgiler eklenmiştir.

\section{İşlem}

Araştırma verileri, İMD kursunun son haftasında sınıf ortamında toplanmıştır. Katılımda gönüllülük esası özellikle gözetilmiş ve katılımcılara mesleki ilgilerine yönelik geribildirim verileceği belirtilmiştir. Geribildirim verileceği bilgisinin katılımcı sayısını ve isteğini artırdığı gözlenmiştir. Araştırmaya katılan tüm bireylere analizler yapıldıktan sonra daha önceden duyurulan internet sitesi aracılı̆̆ıyla mesleki ilgilerine yönelik sonuçlar verilmiştir.

\section{Verilerin Analizi}

Verilerin analiz edilmesinde betimsel istatistiklerden, korelasyondan, bağımsız gruplar için $\mathrm{t}$ testinden yararlanılmış ve görüş belirtenlerin cevapları nitel olarak incelenmiştir. 


\section{BULGULAR}

Bu bölümde önce demografik bulgulara, daha sonra MAİ sonuçlarına yer verilmiştir.

"Bölümünüzü sevme derecenize 1 ile 100 arasında bir puan veriniz (Bölümünüzle ilgili istihdam kaygınızın olmadığını düşünerek)" maddesinin ortalaması 78,06 medyanı ise 80 olarak bulunmuştur. Buna ek olarak kendi alanlarına ait alt boyuttan aldıkları $\mathrm{t}$ puanları ile bölümlerini sevme dereceleri arasında $\mathrm{r}=0,46(\mathrm{p}<.001)$ düzeyinde korelasyon hesaplanmıştır.

Katılımcılara yöneltilen "Üniversite sınavına girseydiniz ve yalnızca ilginizi dikkate alsaydınız hangi bölümü okumak isterdiniz?" sorusuna kendi mezun olduğu bölümle aynı cevabı verenler yalnızca 32 (\%15)'dir. Katılımcıların 29 (\%14)'u bu soruya psikoloji demiştir. “İş ve meslek danışmanı olmasaydınız hangi mesleği yapmak isterdiniz" sorusuna kendi mezun olduğu bölümü yazanlar 57 (\%26) kișidir. Katılımcıların mezun olduğu alanlar, ilgi duydukları alanlar ve yapmak istediği mesleğe ilişkin dağılımları Tablo 1'de yer almaktadır.

Tablo 1. Katılımcıların mezun olduğu alanlar, ilgi duydukları alanlar ve yapmak istediği mesleğe ilişkin dă̆llımlar

\begin{tabular}{rlcccccc}
\hline Mesleki Alanlar & $\begin{array}{c}\text { Mezun } \\
\text { Olduğu } \\
\text { Alan }\end{array}$ & Yüzde & $\begin{array}{c}\text { İgisine } \\
\text { Göre } \\
\text { Alanı* }\end{array}$ & Yüzde & $\begin{array}{c}\text { Yapmak } \\
\text { İstediği } \\
\text { Meslek }\end{array}$ & Yüzde \\
\hline $\mathbf{1}$ & Matematik & 55 & 27,6 & 22 & 12,0 & 21 & 11,9 \\
$\mathbf{2}$ & Bilgisayar & - & - & 4 & 2,2 & 5 & 2,8 \\
$\mathbf{3}$ & Yabancı dil & - & - & 4 & 2,2 & 3 & 1,7 \\
$\mathbf{4}$ & Görsel Sanatlar & 2 & 1 & 19 & 10,4 & 9 & 5,1 \\
$\mathbf{5}$ & Psikoloji & - & - & 25 & 13,7 & 17 & 9,7 \\
$\mathbf{6}$ & Eğitim & 1 & 0,5 & 7 & 3,8 & 32 & 18,2 \\
$\mathbf{7}$ & Türk dili & 9 & 4,5 & 5 & 2,7 & 5 & 2,8 \\
$\mathbf{8}$ & Hukuk & - & - & 15 & 8,2 & 8 & 4,5 \\
$\mathbf{9}$ & Ziraat & - & - & - & - & - & - \\
$\mathbf{1 0}$ & İletişim & - & - & 5 & 2,7 & 3 & 1,7 \\
$\mathbf{1 1}$ & Mühendislik & 8 & 4 & 23 & 12,6 & 16 & 9,1 \\
$\mathbf{1 2}$ & Siyasal-Mali & 2 & 1 & 12 & 6,6 & 5 & 2,8 \\
& Bilimler & & & & & & \\
$\mathbf{1 3}$ & Fen bilimleri & 121 & 60,8 & 11 & 6,0 & 37 & 21,0 \\
$\mathbf{1 4}$ & Sağlık & 1 & 0,5 & 31 & 16,9 & 15 & 8,5 \\
& TOPLAM & $\mathbf{1 9 9}$ & $\mathbf{1 0 0}$ & $\mathbf{1 8 3}$ & $\mathbf{1 0 0}$ & $\mathbf{1 7 6}$ & $\mathbf{1 0 0}$ \\
\hline
\end{tabular}

* Üniversite sınavına girseydiniz ve yalnızca ilginizi dikkate alsaydınız hangi bölümü okumak isterdiniz?" sorusuna cevap olarak belirttiği ilgi alanını belirtmektedir. 
Tablo 1 incelendiğinde IMD adaylarından 121 kişinin fen bilimleri alanlarından (fizik, kimya, biyoloji, astronomi, fizik öğretmenliği, kimya öğretmenliği vb.), 55 kişinin de matematik alanından (matematik, matematik öğretmenliği, ilköğretim matematik öğretmenliği) mezun olduğu görülmektedir. Katılımcılar ilgilerini dikkate alarak eğitim alsalardı, farklı alanlarda (özellikle sağlık, psikoloji, mühendislik, matematik) eğitim görmüş olacaklardı. Fen bilimleri alanından mezun olan 121 (\%61) katılımcının yalnızca $11(\% 6)$ 'i; Matematik alanından mezun olan 55 (\%28) katılımcının 22 (\%12)'si ilgisini dikkate alarak tercih yapsaydı kendi alanını okumak istediğini belirtmektedir. Buna ek olarak Fen bilimleri alanındakilerden 37 (\%21)'si; Matematik alanındakilerden 21 (\%12)'i "IMD olmasaydınız hangi mesleği yapmak isterdiniz?" sorusuna kendi alanını belirtmişlerdir.

\section{Mesleki Alan İlgi Envanteri (MAI) Puanlarından Elde Edilen Bulgular}

Katılımcıların özellikle Fen bilimleri ve Matematik alanlarında yığılmaları sebebiyle MAİ'nin alt boyutlarından elde edilen puanların karşılaştırılması mümkün olmamıştır. MAI'nin her alt boyutu için yalnızca cinsiyet açısından karşılaştırma yapılmıştır. Cinsiyete ilişkin MAİ alt boyutlarının farkının t testi ile karşılaştırılması Tablo 2'de verilmiştir. 
Tablo 2. Cinsiyete göre MAI alt boyutlarının ortalamalarının farkının testi

\begin{tabular}{|c|c|c|c|c|c|}
\hline & Cinsiyet & $\overline{\bar{X}}$ & $\mathbf{S}_{\mathbf{x}}$ & $\mathbf{t}$ & $\bar{K}-\mathbf{E}$ \\
\hline \multirow[t]{2}{*}{ Matematik } & Kadın & 51,71 & 10,79 & $-0,99$ & $-1,50$ \\
\hline & Erkek & 53,22 & 9,76 & & \\
\hline \multirow[t]{2}{*}{ Bilgisayar } & Kadın & 42,60 & 10,90 & $-5,61 * * *$ & $-8,64$ \\
\hline & Erkek & 51,25 & 10,19 & & \\
\hline \multirow[t]{2}{*}{ Yabancı dil } & Kadın & 47,14 & 11,24 & $-0,62$ & $-0,97$ \\
\hline & Erkek & 48,11 & 9,53 & & \\
\hline \multirow[t]{2}{*}{ Görsel sanatlar } & Kadın & 50,47 & 11,08 & 1,65 & 2,50 \\
\hline & Erkek & 47,97 & 9,29 & & \\
\hline \multirow[t]{2}{*}{ Psikoloji } & Kadın & 56,09 & 11,30 & $4,77 * * *$ & 7,43 \\
\hline & Erkek & 48,65 & 9,70 & & \\
\hline \multirow[t]{2}{*}{ Ĕgitim } & Kadın & 53,30 & 11,06 & $2,32 *$ & 3,52 \\
\hline & Erkek & 49,77 & 9,35 & & \\
\hline \multirow[t]{2}{*}{ Türk dili } & Kadın & 44,84 & 10,19 & $-1,36$ & $-2,18$ \\
\hline & Erkek & 47,03 & 12,66 & & \\
\hline \multirow[t]{2}{*}{ Hukuk } & Kadın & 46,09 & 11,47 & $-1,57$ & $-2,43$ \\
\hline & Erkek & 48,53 & 9,17 & & \\
\hline \multirow[t]{2}{*}{ Ziraat } & Kadın & 47,39 & 11,11 & $-0,61$ & $-0,93$ \\
\hline & Erkek & 48,32 & 9,30 & & \\
\hline \multirow[t]{2}{*}{ İletişim } & Kadın & 46,92 & 10,58 & $-1,59$ & $-2,43$ \\
\hline & Erkek & 49,36 & 10,70 & & \\
\hline \multirow[t]{2}{*}{ Mühendislik } & Kadın & 44,02 & 10,26 & $-5,82 * * *$ & $-8,73$ \\
\hline & Erkek & 52,75 & 10,63 & & \\
\hline \multirow[t]{2}{*}{ Siyasal-mali bilimler } & Kadın & 45,19 & 9,70 & $-4,20 * * *$ & $-6,25$ \\
\hline & Erkek & 51,44 & 11,34 & & \\
\hline \multirow[t]{2}{*}{ Fen bilimleri } & Kadın & 51,70 & 10,26 & 0,58 & 0,85 \\
\hline & Erkek & 50,85 & 9,83 & & \\
\hline \multirow[t]{2}{*}{ Sağlık } & Kadın & 51,94 & 11,37 & $2,87 * *$ & 4,44 \\
\hline & Erkek & 47,50 & 9,26 & & \\
\hline
\end{tabular}

Tablo 2 incelendiğinde bilgisayar $\left(\mathrm{t}_{(211)}=-5,61\right)$, mühendislik $\left(\mathrm{t}_{(211)}=\right.$ $5,82)$ ve siyasal-mali bilimler $\left(\mathrm{t}_{(211)}=-4,20\right)$ alanlarında erkeklerin ilgi puanı ortalamalarının kadınlarınkinden anlamlı bir şekilde daha yüksek olduğu görülmektedir $(p<0,001)$. Öte yandan psikoloji ( $\left.t_{(211)}=4,77\right)$, eğitim $\left(\mathrm{t}_{(211)}=2,32\right)$ ve sağlık $\left(\mathrm{t}_{(211)}=2,87\right)$ alanlarında kadınların ilgi puanı ortalamalarının erkeklerinkinden anlamlı bir şekilde daha yüksek olduğu görülmektedir $(\mathrm{p}<0,01)$.

Bu çalışmada İMD adayları Psikoloji alt boyutundan aldıkları puanlar açısından standart $\mathrm{t}$ puanları kullanılarak incelenmiştir. $\mathrm{T}$ puanları farklı ortalama ve standart sapmalara sahip dağılımların karşılaştırılmasında standart sağladığı için tercih edilmiştir. IMMD'ler mesleki karar verme aşamasındaki bireylere danışmanlık yapmaktadırlar. Bununla birlikte eğitim sırasında IMD adaylarının özgeçmişlerine ve mezun oldukları bölümlere 
iliş̧in ciddi eleştirilerin yöneltildiği araştırmacı tarafindan gözlemlenmiştir. Katılımc1ların 128 (\%60)'inin psikoloji t puanı 50'nin üzerinde, bunlardan 76 (\%35)'sının psikoloji t puanı 60 (\%28)'ın üzerindedir. Bu bulgu İMD adaylarının her ne kadar psikoloji eğitimi veren bir bölümden mezun olmasalar da psikolojiye yönelik ilgilerinin oldukça yüksek olduğunu göstermektedir.

Katılımciların mezun olduğu bölümle MAİ'nin kendi bölümüyle alakalı alt boyutundan aldığı puan, standart t puanları kullanılarak incelenmiştir. Çünkü t puanları normal dağılıma dayalı olarak ortalamaları farklı olan dağılımlar içinde standart bir karşılaştırma imkanı sunmaktadır. Bulgular incelendiğinde 154 (\%71) kişinin ilgili alt boyuttan aldığı t puanı 50'nin üzerinde, bunlardan 93 (\%43)'ünün ise t puanı 60'nn üzerindedir. Bu bulgu Benzer bir bulgu olarak, katılımcılardan 164 (\%76)'ünün yalnızca ilgisini dikkate alarak okumak istediği bölümle ölçeğin ilgili alt boyutundan aldığı t puanı 50 ve üzerinde, bunlardan 118 (\%55)'inin t puan1 ise 60'1n üzerindedir. $\mathrm{Bu}$ bulgular katılımcıların önemli bir bölümünün kendi bölümlerine ilişkin ilgilerinin ortalamanın üzerinde olduğunu göstermektedir.

\section{TARTIŞMA VE SONUÇ}

Araştırma bulguları incelendiğinde bölümlerini sevme puanları açısından sola çarpık bir dağılım elde edildiği gözlenmiştir. Bu durum katılımcıların mezun oldukları bölümü sevdikleri şeklinde yorumlanabilir. Katılımcıların kendi alanlarına ait MAİ alt boyutundan aldıkları t puanları ile bölümlerini sevme dereceleri arasında istatistiksel olarak anlamlı korelasyon bulunmuş olsa da hesaplanan değer orta düzeydedir. Türkiye'de mesleki rehberliğin öneminin yeterince anlaşılmayışı ve tüm kesimlerde tam olarak yaygınlaşmamış olması bireylerin ilgilerinden uzak bölümlere yönelmelerine neden oluyor olabilir.

Öte yandan katılımcıların büyük bölümü tekrar aynı bölümü seçmek istemediğini belirtmiştir. Bununla birlikte kendi mezun olduğu alanda çalışmak isteyenlerin sayısı aynı bölümde okumak isteyenlerden biraz daha fazladir.

Katılımcıların çoğunlukla fen bilimleri ve matematik alanlarından mezun kişilerden oluşmasına rağmen bunlardan çok azı bölümünün kendi ilgisine uygun olduğunu düşünmektedir.

MAİ puanlarından elde edilen bulgular incelendiğinde bilgisayar, mühendislik ve siyasal-mali bilimler alanlarında erkeklerin, psikoloji, eğitim ve sağlık alanlarında kadınların karşı cinse göre ilgilerinin daha öne çıktığ 1 sonucuna ulaşılabilir. Literatür incelendiğinde kadınların ilgilerinin daha çok 
insanlarla çalışma gerektiren meslekler olduğu görülmektedir (Tay, Drasgow, Rounds ve Williams, 2009; Su, Rounds ve Armstrong, 2009; Lippa, 1998, 2005; Low, Yoon, Roberts ve Rounds, 2005; Rounds, 1995). Literatürle birlikte kendi gözlemlerimiz de bunu desteklemektedir. Örneğin, şu anda gözümüzü kapatıp mühendis dediğimizde aklımıza erkek, öğretmen dediğimizde ise çoğunlukla kadın gelir. Elbette bu mesleklere ilişkin istisnai durumlar olabilir. Buradan Low ve Rounds (2007)'un tespitlerine gidilebilir. $\mathrm{Bu}$ araştırmacılara göre kadınlar ve erkekler kendi cinsiyeti için toplum tarafindan biçilmiş mesleki etkinlik ve meslek tercihini yapmaya yönlendirilir. Deng, Armstrong ve Rounds (2007) da benzer bulgulara dayanarak erkeklere Holland'ın gerçekçi kişilik tipine uygun mühendislik benzeri meslekleri, kadınlara ise öğretmen, psikolog gibi insanlarla çalışma gerektiren sosyal meslekleri önermişlerdir. Türkiye'de yapılan çalışmalar incelendiğinde Sayın (2000)'ın cinsiyetin mesleki ilgileri yordayıcı bir değişken olduğu bulgusu bu araştırma bulgularına paralel sonuçlar olarak görülmektedir. Deniz (2013)'in standardizasyon çalışmasında da bu araştırma bulgularına paralel olarak insanla çalışma gerektiren mesleklere kadınların, madde ile çalışma gerektiren mesleklere erkeklerin ilgilerinin karşı cinslerine göre anlamlı farklılık göstermektedir. Buna ek olarak Uzer (1987) kız öğrencilerin ilgilerine daha uygun mesleki tercihte bulunduklarını vurgulamaktadır.

MAİ'de 14 alt boyut olmakla birlikte İMD adaylarının yapacakları iş ve görev tanımları dikkate alındığında Psikoloji alt boyutuna ait puanlar özellikle incelenmiştir. Bu boyuta ait bulgular sonucunda katılımcıların çoğunluğunun ilgisinin ortalamanın üzerinde olduğu sonucuna ulaşılmıştır. Buna ek olarak psikoloji bölümünde okumak isteyen katılımcıların oranı da \%14'tür. Her ne kadar IMD kursuna katılanların temel gerekçesi kendi bölümündeki işsizlik olsa da, katılımcıların \%65'inin kadın, \%35'inin erkek olması MAİ Psikoloji alt boyutundaki anlamlı çıkan cinsiyet farkına ilişkin sonuçları desteklemektedir. Kadınlar insanlarla çalışma gerektiren bir mesleğe erkeklerden daha fazla oranda yönelmişlerdir.

Katılımciların mezun olduğu bölümle, MAİ'nin kendi bölümüyle alakalı alt boyutundan aldığı puana ilişkin bulgulardan büyük çoğunluğun kendi bölümüne ait ilgilerinin ortalamanın üzerinde olduğu sonucu dikkat çekmektedir. Benzer şekilde yalnızca ilgisini dikkate alarak okumak istediği bölüm sorusunun cevabı ile bu cevaba karşıllk gelen ilgili alt boyuttan katılımcıların büyük çoğunluğunun ortalamanın üzerinde puan aldığı sonucuna ulaşılmıştır. Bu sonuçlar katılımcıların ilgilerine uygun bölümlerde okumadıkları bulgularının aksini göstermektedir. Bu noktada katılımcıların bölümlerine isteyerek girmiş olabilecekleri ancak iş kaygısı ve okul 
ortamındaki yaşantıları sonucunda ilgilerinin azalmış olabileceği yorumuna da gidilebilir.

Yeni yapılacak olan çalışmalarda farklı ilgi envanterleri kullanılarak benzer değișkenler açısından durum incelenebilir. Bu çalıșmada ağırlıklı olarak sözel diye tabir edilecek bir bölümde çalışmak üzere olan çoğunluğu sayısal bölüm mezunu grup üzerinden bulgular elde edilmiştir. Yeni çalışmalarda MAİ'nin bütün alanlarıyla alâkalı daha geniş bir grup üzerinde araştırma yapılabilir. Bu çalışmada İMD adaylarının kendi bölümlerine ve psikoloji alanına ilişkin ilgileri incelenmiştir. Yeni çalışmalarda insanlarla iletişim kurmak gereken farklı alanlara ilişkin ilgiler de araştırılabilir. Ayrıca bu çalışma kapsamında incelenmeyen sosyo-ekonomik düzey ve başarı gibi mesleki ilgiyle alakalı değişkenler de yeni yapılacak araştırmalarda dikkate alınabilir. Bu araştırma sonunda elde edilen cinsiyete ilişkin bulgular dikkate alındığında mesleki rehberlik aşamasında cinsiyetin dikkate alınması gerektiği görülmektedir.

\section{KAYNAKLAR}

Betsworth, D. G., \& Fouad, N. A. (1997). Vocational interests: A look at the past 70 years and a glance at the future. The Career Development Quarterly. 46, 1, pp. 23-47. DOI: 10.1002/j.2161-0045.1997.tb00689.x Article first published online: 23 DEC 2011.

Bütün, A. (1998). Farklı sosyo-ekonomik düzeylerdeki genel liselere ve kız meslek liselerine devam eden klz ögrencilerin mesleki ilgilerinin incelenmesi. Yayımlanmamış doktora tezi. Ankara Üniversitesi, Fen Bilimleri Enstitüsü, Ankara.

Deng, C-P., Armstrong, P. I., \& Rounds, J. (2007). The fit of Holland's RIASEC model to US occupations. Journal of Vocational Behavior, 71, 1-21.

Deniz K. Z. (2013). National standardization of the Occupational Field Interest Inventory (OFII) for Turkish Culture according to age and gender. Eğitim Arastırmalar1 - Eurasian Journal of Educational Research, 50, 163-184.

Deniz, K. Z. (2009). Occuppational Field Interest Inventory (OFII) development study. Y.Y. Üniversitesi, Eğitim Fakültesi Dergisi. Cilt:VI, Sayı:I, 289-310 http://efdergi.yyu.edu.tr

Deniz, K. Z. (2008). Uzmanlık gerektiren mesleklere yönelik bir ilgi envanteri geliştirme çalışması. Yayımlanmamış doktora tezi. Ankara Üniversitesi Eğitim Bilimleri Enstitüsü, Ankara.

Herr, E.L., \& Cramer, S. H. (1996). Career guidance and counseling through the lifespan (5th Ed). Longman Inc.

Holland, J. L. (1985). Making vocational choices: A theory of vocational personalities and work environments. (2nd Ed). USA: Prentice Hall. 
İŞKUR (2012). İş ve Meslek Danışmanlığı Hizmetleri, 21.03.2012 tarihinde http://www.iskur.gov.tr/LoadExternalPage.aspx?uicode=statisvemeslekdanism anlig adresinden alınmıştır.

İMD Hizmetleri (2012). 16.07.2012 tarihinde https://www.turkiye.gov.tr/is?icerik= $\% \mathrm{C} 4 \% \mathrm{~B} 0 \% \mathrm{C} 5 \% 9 \mathrm{~F} / \% \mathrm{C} 4 \% \mathrm{~B} 0 \% \mathrm{C} 5 \% 9 \mathrm{~F}+$ $\mathrm{ve}+$ Kariyer/Mesleki+E $\% \mathrm{C} 4 \% 9$ Fitim $/ \% \mathrm{C} 4 \% \mathrm{~B} 0 \% \mathrm{C} 5 \% 9 \mathrm{~F}+\mathrm{ve}+$ Meslek+Dan $\% \mathrm{C}$ 4\%B1\%C5\%9Fmanl\%C4\%B1\%C4\%9F\%C4\%B1+Hizmetleri adresinden alınmıştır.

İşKUR'dan İş ve Meslek Danışmanlığı Eğitimi (2012). 20.06.2012 tarihinde http://www.imd.org.tr/new/index.php/haberler/1-son-haberler/413-kurdan-vemeslek-danmanl-eitimi adresinden alınmıştır.

Lippa, R. A. (1998). Gender-related individual differences and the structure of vocational interests: The importance of the people-things dimension. Journal of Personality and Social Psychology, 74, 996-1009.

Lippa, R. A. (2005). Subdomains of gender-related occupational interests: Do they form a cohesive bipolar M-F dimension? Journal of Personality, 73, 693-729.

Lokan, J.J. (1997). Vocational Interests and Aptitudes, Measures of. In J.P.Keeves (Ed), Educational Research, Methodology, and Measurement: An International Handbook (2nd Ed). Pergamon Press, UK.

London, H.J.E., Würzburg, W. A, \& Berne, R.M (Eds) (1972). Encyclopedia of Psychology, The Seabury Press, New York, USA

Low, K. S. D., \& Rounds, J. (2006). Vocational interests: Bridging person and environment. In D. L. Segal \& J. Thomas (Eds.), Comprehensive handbook of personality and psychopathology, Volume I: Personality and everyday functioning (pp. 251-267). NY: Wiley

Low, K. S. D., \& Rounds, J. (2007). Interest change and continuity from early adolescence to middle adulthood. International Journal of Educational and Vocational Guidance, 7, 23-36.

Low, K. S. D., Yoon, M., Roberts, B. W., \& Rounds, J. (2005). The stability of vocational interests from early adolescence to middle adulthood: A quantitative review of longitudinal studies. Psychological Bulletin, 131, 713-737.

Organisation for Economic Co-operation and Development and European Commission(OECD) (2004). Career guidance: A handbook for policy makers. 21.02.2012 tarihinde www.oecd.org/dataoecd/53/53/34060761.pdf adresinden alınmıştır.

Öktem, C. (2000). Lise son sinıf ögrencilerinin alglladıkları ana-baba tutumlarının mesleki ilgi ve değerleriyle iliş̧kisi.Yayımlanmamış yüksek lisans tezi. Uludağ Üniversitesi, Sosyal Bilimler Enstitüsü, Bursa.

Repetto, E., Malik, B., Ferrer-Sama, P., Manzano, N., \& Hiebert, B. (2003). International competencies for educational and vocational guidance practitioners: Final report to the General Assembly of the International Association for Educational and Vocational Guidance. Bern, Switzerland. 20.02.2012 tarihinde http://www.iaevg.org/IAEVG/ adresinden alınmıştır.

Rounds, J. B. (1995). Vocational interests: Evaluation of structural hypotheses. In D. Lubinski \& R. V. Dawis (Eds.),Assessing individual differences in human 
behavior: New concepts, methods, and findings (pp. 177-232). Palo Alto, CA: Consulting Psychologists Press.

Savickas, M.L. (1999). The Psychology of Interests. In M.L. Savickas and A.R. Spokane (Eds.), Vocational Interests: Meaning, Measurement and Counseling Use. USA: Davies-Black.

Sayın, S. (2000). Lise ögrencilerinin mesleki ilgilerini yordayan bazı değişkenler. Yayımlanmamış doktora tezi. Hacettepe Üniversitesi, Sosyal Bilimler Enstitüsü, Ankara.

Su, R., Rounds, J. \& Armstrong, P. I. (2009). Men and things, women and people: A meta-analysis of sex differences in interests. Psychological Bulletin, 135, 859884.

Tay, L., Drasgow, F., Rounds, J., \& Williams, B. A. (2009). Fitting measurement models to vocational interest data: Are dominance models ideal? Journal of Applied Psychology, 94, 1287-1304.

Uzer, A.S. (1987). Lise öğrencilerinin yükseköğretim programlarını tercihleri ile kendi yetenek, ilgi ve mesleki olgunluk düzeyleri arasındaki ilişkiler. Yayımlanmamış doktora tezi. Hacettepe Üniversitesi, Sosyal Bilimler Enstitüsü, Ankara.

Vondracek, F. W. \& Skorikov, V. B. (1997). Leisure, school, and work activity preferences and their role in vocational identity development. The Career Development Quarterly. 45, 322-340. Article first published online: 23 DEC 2011 DOI: 10.1002/j.2161-0045.1997.tb00537.x

Yaman, M., Gerçek, C. ve Soran, H. (2008). Biyoloji öğretmen adaylarının mesleki ilgilerinin farklı değişkenler açısından incelenmesi. Hacettepe Üniversitesi Eğitim Fakültesi Dergisi, 35, 351-361.

Yeşilyaprak, B. (2012). Mesleki rehberlik ve kariyer danışmanlığında paradigma değişimi ve Türkiye açısından sonuçlar: Geçmişten geleceğe yönelik bir değerlendirme. Kuram ve Uygulamada Eğitim Bilimleri, 12/1, 111-118. 
